\title{
Identifying the influence of quality management of ISO 9001 on product innovation and financial turn over interfering the lack of peripheral confidence
}

\author{
Ghaem AGHAEI ${ }^{1, *}$, Mahmoud DASHTBOZORG ${ }^{2}$, Maryam Bavarsad AhMAdPOUR ${ }^{3}$. \\ ${ }^{1}$ MA in executive management, Administrative Expert of Khuzestan Regional Electricity Company \\ ${ }^{2} \mathrm{PhD}$ student of Public Administration, Islamic Azad University of Shushtar ‘Iran, Khuzestan \\ Regional Electricity Company Director; email address: mdashtbozorg@kzrec.co.ir \\ ${ }^{3}$ Computer experts, Khuzestan Regional Electricity Company; \\ email address: maryambvrsd@yahoo.com \\ * corresponding author: ghaem_aghaei@yahoo.com, Telephone Number:00989166017385
}

\begin{abstract}
This paper aims at identifying the influence of Quality Management of ISO 9001 on product innovation and financial turn over interfering the lack of peripheral confidence. The population includes 90 employees of industrial factories around Ahvaz and in Ahvaz-Shooshtar road who were selected through random sampling. Stability and the validity of the mentioned questionnaire were also evaluated in this research. Data analysis was performed via descriptive and inferential analysis and also SPSS18 and Lisrel8.5 and approved by confirmatory factor and goodness of fit for four variables. The results coming from the hypothesis test confirm the both the hypothesis and the influence of ISO 9001 Quality Management on financial turn over and the innovation. Also the turn over itself is effective in product innovation but the inferential role of lack of peripheral confidence on ISO 9001 Quality Management on financial turnover and the product innovation was not approved.
\end{abstract}

Keywords: Quality Management, Product Innovation, financial turn over, lack of peripheral confidence.

\section{Introduction}

Today the global contest is the way the organizations have to improve their quality, increasing the customer satisfaction, reducing the costs and increasing the productivity simultaneously. The existence of such atmosphere has led to the advent of diverse methods and approaches such as comprehensive quality management. Planning and applying the quality management system is affected by various needs, specific objectives, the product, used process, the size and the structure of the organization. Accepting the quality management system in an organization will be a strategic decision making. The consistent and acceptable quality of the products and the services is of the most efficient of the company in a successful strategy. Standardizing the management and the manahes\&apos; activity has been counted as of the solutions toward success in developed countries. Wide movements toward standardizing the management in our country using ISO 9001represents fundamental evolutions in management [2]. In this between ISO 9001as the organizational evolution and also improving the social situation of organizations are of the important adminstrative 
affairs used in productive and service organizations. Hence, commitment toward observing the provisions for such standards and making internal and consistent belief in senior managers in the society is of the primary qualifications for such standards [3].

Today the quality of the product and the services has a vital role in international economy. In other words the consistency and the growth of the companies in National and Global markets depends on fulfilling the qualifications of a product such as quality in customer's view. In this sense the quality management systems are of the proper equipments applied in order to provide expected quality level consistently and repetitively. Since ISO 9001 can be applied as a tool to improve the markets and the way they operate, acquiring ISO 9001 can be counted as one of the strategic and long-term plans for many of the companies. mostly two reasons why companies intend to acquire ISO 9001 are as follows:

A. Performing comprehensive quality management [4].

B. Taking use of competitive benefits[5].

In this sense and due to the importance of the concept quality and considering the growing increase in qualitative attitude the world standards Institute has started to codify standards in order to establish quality management system and guarantee the quality under ISO 9001 standard series. Which is the first version of international standard series from ISO 9001 representing the first Quality Management Systems sample codified in 1985. Due to the increasing acceptance of the second version of the mentioned standard in the world (durin the recent years). It has implicitly turned into an unofficial and unavoidable obligation in international trade. Also this issue has been discussed as a crisis for service and industrial companies in Iran and some other parts of the world. on the other hand the managers in companies and organizations managers get their energy from the customer\&apos;s satisfaction and organizational survival which are the main philosophy of the comprehensive quality management. The comprehensive quality management has been announced as a holistic quality approach for companies aiming at improving their operation toward quality during the last two decades. The organizations using quality management have a variety of benefits including producing better quality products, higher customer satisfaction, lowering the costs, financial improvements, quality and also Innovations in how to operate and also the employees' satisfaction is gained. In addition if the quality management is applied properly it will be counted as a competitive benefit. Studies have shown a positive relation between the organizational results and the quality management.

Lack of peripheral confidence note the managers understanding about external factors such as competitors, production technology and the market demand. French factors are effective in the manager's need toward accounting information. Therefore when the level of lack of peripheral confidence is high the manager needs to complicated accounting system in order to counteract the unreliable environment and making more appropriate decisions. On the other hand in low levels for lack of peripheral confidence traditional and simple accounting information works better. Therefore it is argued that taking use of complicated accounting systems for the time then we have a low peripheral confidence and providing a torrent of organizational information may not be appropriate. Therefore when the operation of the organization is not Optimum the accounting management is in accordance with the lack of peripheral confidence, therefore the companies experiencing the incongruity will be punished [6].Tutorial open systems have taken the environment of the organization at the system outside the organization affecting the manner and the abilities of the 
companies. Dynamism and lack of peripheral confidence can you stem from the changes in technology, the variety in customer's experiences, the fluctuations in demands for supplying the raw materials. The organization of open systems are exploring kind of balance with their outside environment. Therefore the organization change their strategy, their structure and their process in response to lack of peripheral confidence [7].

On the other hand innovation has an important role in competitive advantage in competitions today. As mentioned by Nodler and Tashman " in the marketing environment today there is no administrative Duty more important than innovation and the change management, therefore for competing in all changing environment the companies have to provide new product, new services and process and try to get adopted with new innovations. Innovation is taken as an idea or manner related to a product, a service, a device, a policy or the plans accepted by the organization. The Innovation must be a process including offering a new plan, acquiring the necessary knowledge in different ways, turning an idea or knowledge or a technology into the service and offering that service or product to the society end it's being accepted by the customer. Considering the competetive pressure in the market, measuring Innovative operation is of a great importance end experts and the users are looking for proper indexes to study the operation of Innovations and in the performed researches the positive relation between the Innovative operation and organizational operation has been approved. The quality management is adopted with the innovation doctrines. And the comprehensive quality management is now as making and organizational and cultural system which results in developing Innovations[8].

In recent years the organizational managers and ideologists have paid special care to innovation any relation between environment and innovation has been of a great importance, most organizations have been facing environmental changes increasingly. Of the important challenges for the organizations today is to answer environmental conditions and getting adopted with its pressures. Recently and in response to such challenges many organizational ideologist have tried to identify special organizational features which are the most appropriate for peripheral changes [9]. In order to increase the competitive advantage the companies have to realize the peripheral factors well and understand the effect of lack of peripheral confidence which are effective in innovations. Considering the issues mentioned so far this is studying aims to identify the ISO 9001 quality management and its effect on product innovation and financial turnover interfering the lack of peripheral confidence as the researcher is about to answer this main question that if the ISO 9001 quality management is effective in product Innovation and financial turnover using interfering role of lack peripheral confidence?

Hosni Tvabe\&apos;, Kazemi and Maharati have made a study named: "the effects of lack of peripheral confidence on organizational innovation:specifying for you the role of organizational instructure as an interfering factor". The results from the day together from the population of 89 senior managers show that the conceptual model I\&apos; ve had it proper fitness and the relation between the lack of a peripheral confidence and organizational structure such as concentration, formality and complication of organizational structure with Innovation was significant. What\&apos;s the relation between centralisation and Innovation was not significant as a result the complications mediator and the formality of organizational structure was significant in the relation of lack of peripheral confidence and The Innovation therefore it was approved but the role of centralization mediator was not approved [6]. 
Benner and Touchman (2003)[10] realized comprehensive quality management could not prevent updating Innovations. In a research reviewing the integrity between comprehensive quality management and the technology management it was specified that the comprehensive quality management has a powerful prediction for qualitative operation of the organization but there is no significant relation with operations of innovation [11]. Another research effects of comprehensive quality management on Innovations in developing countries come to the conclusion that the comprehensive quality management has a positive effect on organizational innovation [12].

\subsection{The objectives}

1. Identifying the effects of ISO 9001 on innovation.

2. Identifying the effect of ISO 9001 management system on the financial turnover of the companies

3. Identifying defective products innovation on the company\&apos;s turnover

4. lack of peripheral confidence effects the relation between ISO 9001 and the innovation Methodology

\subsection{The method}

This is a survey research on the basis of primary data and it is practical in terms of objective because it concentrates on developing the Practical knowledge about the variables and since it describes in conditions and reviewed phenomena and also implies they effects of variables and their relations, it is descriptive on the basis of data collection and causative on the basis of research.

\subsection{Data collection tools}

In this research the data collection tool in the library method includes books, magazines and essays, thesis and also the internet. And also in the field is study the collection tool is the questionnaire. The questions of the questionnaire are divided into two parts as general questions and specific equations such as age, job experience and education. This specific questions are presented in the form of the questionnaire related to the variables of the research.

The population, the sample and the sampling method

The population of This research includes the employees of industrial factories in a Ahvaz in Ahvaz-Shoushtar road. It was a simple random sampling including 90 people.

\subsection{The analysis}

The data analysis is performed in two levels as descriptive and a level with SPSS 16 and PLS8.5. Of to review the demographic features the descriptive statistics in SPSS are used then since the questinnaire have been used in other researches and their reliability and validity are reported as acceptable to calculate the reliability of the questionnaire Crunbach has been taken in use. And finally to test the hypothesis the structural equations model has been used through PLS 8.5.

structural equations model has been used through PLS 8.5. 


\section{Data analysis}

1. The demographic features of the respondents and population.

The respondents based on sexuality

Table1: The demographic features of the respondents

\begin{tabular}{|c|c|c|c|}
\hline Percent & Measure & & \\
\hline 61.1 & 55 & Male & \\
\hline 38.9 & 35 & Female & Gender \\
\hline 100.0 & 90 & Total & \\
\hline
\end{tabular}

As can be seen in table among 90 respondents 55 people which is equal to $61 \%$ are male and the rest 45 people which is equal to $38.9 \%$ are female. The number of valid observations is 90 and there is no non answered case.

The respondent in terms of age

Table 2: Demographic features of the participants

\begin{tabular}{ccr} 
Percent & Measure & \\
\hline 22.2 & 20 & years old 30 to 20 \\
\hline 54.4 & 49 & years old 40 to 31 \\
\hline 15.6 & 14 & years old 50 to 41 \\
\hline 7.8 & 7 & Above 50 \\
\hline 100.0 & 90 & Total
\end{tabular}

According to table 2 the age of respondents have been classified into four levels which the most is related to age of 31 to 40 including the 49 people as $54.4 \%$ and the leaf is for the ages 50 and above which is about 7 people equals $7.8 \%$.

The respondents in terms of Education

Table 3: Demographic features of the respondents

\begin{tabular}{ccc} 
Percent & Measure & \\
\hline 12.2 & 11 & Diploma \\
\hline 51.1 & 46 & BA \\
\hline 30.0 & 27 & MA \\
\hline 6.7 & 6 & Phd \\
\hline 100.0 & 90 & Total
\end{tabular}

According to table 3 educational level is classified into four groups in which the most is related to ba which includes 46 people equal to $51.1 \%$ and the least is for $\mathrm{PhD}$ which includes 6 people equals $6.7 \%$.

The respondent's feature in terms of major 
Table4: The demographic features of respondents

\begin{tabular}{ccc} 
Percent & Measure & \\
\hline 6.7 & 6 & Professional healthcare \\
\hline 23.3 & 21 & Metallogy \\
\hline 15.6 & 14 & Industrial production \\
\hline 27.8 & 25 & Industrial management \\
\hline 17.8 & 16 & Chemical engineering \\
\hline 8.9 & 8 & mechanical engineering \\
\hline 100.0 & 90 & Total
\end{tabular}

As can be seen in table 4 the manager of the respondents is classified into six groups which the highest is about 25 people which equals $27.8 \%$ for industrial engineering and then metallurgy with 21 people which is equal to $23.3 \%$ and the list is related to professional Healthcare width 6 people which is equal to $6.7 \%$.

\subsection{Confirmatory factor analysis of the variables}

In inferential factor analysis the ability of the structure is tested through confirmatory factor analysis of the variables before the hypothesis is tested. also the $\mathrm{T}$ value of each variable is higher than +1.96 and less than -1.96 . It has a good Fitness and has a rational estimation of the society.

\subsection{Measuring model of ISO 9001}

The charts mention that follows show the ISO 9001 model as standard and significant mode. As shown in the chart the membership of all considered factors are approved.

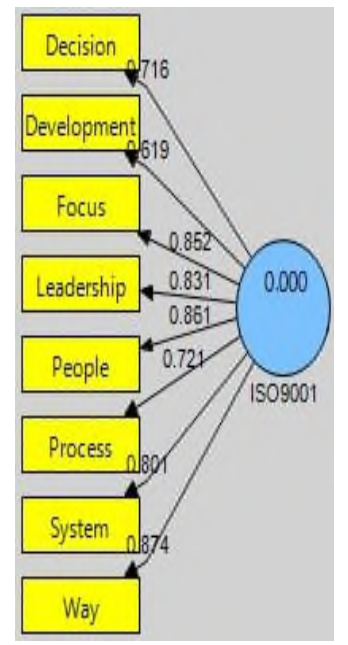

Chart 1: Measuring ISO 9001 model using a confirmatory factor in standard mode 


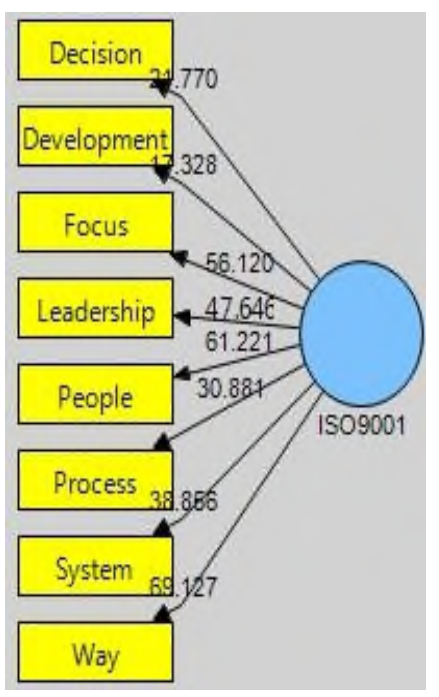

Chart 2: Measuring model of ISO 9001 using factor analysis.

\subsection{Measuring innovation of a product}

The following charts show the Innovation dimensions of a product in standard and significance mode. As shown in the chart a membership of all factors of this variable is approved.

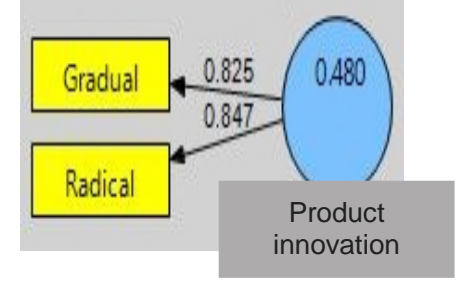

Chart3: Measuring model of product innovation using factor analysis.

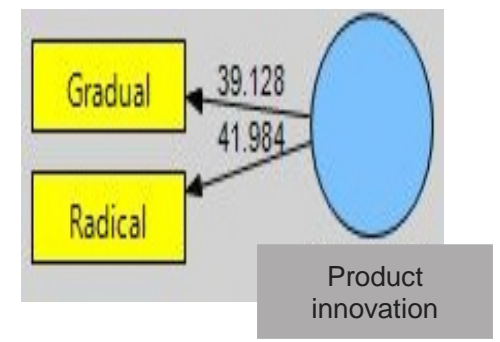

Chart 4: Measuring the dimensions of product innovation using factor analysis in significance mode

\subsection{Operation measuring model}

Charts below show the dimensions of operation in standard and significance mode. The membership of all considered factors is approved. 


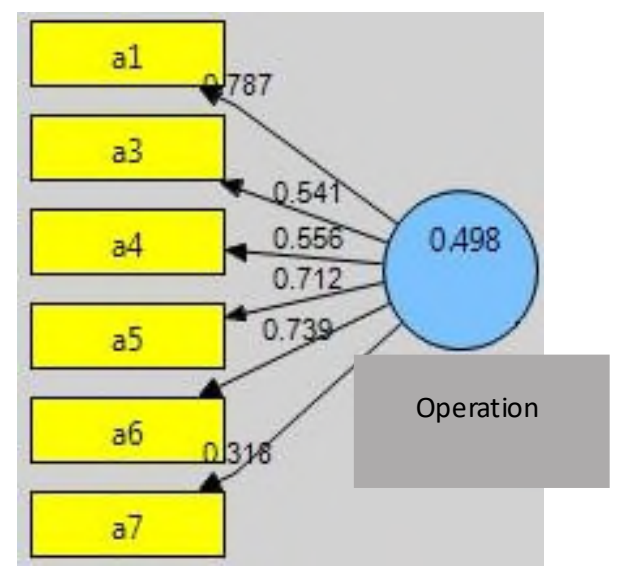

Chart 5: Measuring of operation Dimensions model using factor analysis in standard mode

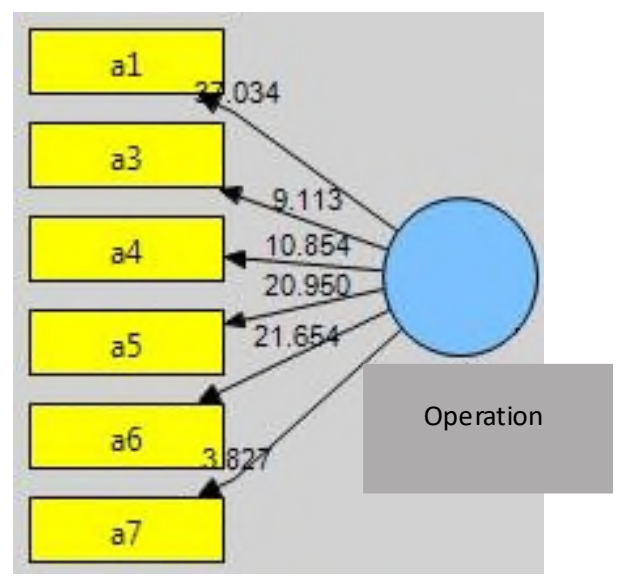

Chart6: Measuring operation Dimensions model using factor analysis in significance mode.

\subsection{Reviewing normal distribution of variables}

Before testing the relations between variables it is necessary to test the variables being normal. What are the methods to review the normal distribution of variables is taking use of Kolmogorov-Smirnov test. The result is shown in the following table. Do the variables have normal distribution?

Zero hypothesis: the variables have normal distribution?

Hypothesis 1: the variables don't have normal distribution.

Table5: Normal distribution of variables

\begin{tabular}{ccc} 
Item & $\begin{array}{c}\text { Culmogrof } \\
\text { Smirov }\end{array}$ & Significance \\
\hline ISO9001 & 0.671 & 0.759 \\
\hline Innovation & 0.783 & 0.572 \\
\hline Lack of peripheral confidence & 0.888 & 0.409 \\
\hline Operation & 0.649 & 0.749
\end{tabular}


According to Table 5 after results show the significance level of this test is above 0.05 Andy SPSS has realized this test as normal therefore the zero hypothesis is confirmed.

\subsection{Reloability}

Reliability is evaluated through 2 criteria 1 . Alpha 2. Composite reliability

Cronbach's alpha

Table6: Cronbach's alpha coefficients

\begin{tabular}{cc} 
& Cronbachs Alpha \\
\hline ISO9001 & 0.910937 \\
\hline Product innovation & 0.712624 \\
\hline Operation & 0.779892 \\
\hline Lack of peripheral confidence & 0.824635
\end{tabular}

\subsection{Composite reliability $(\mathbf{C R})$}

Since the Crunbach Alpha is a traditional scale to specify the reliability of the structures in PLS a more modern method than Alpha named as Composite Reliability is applied and its superiority over Chrunbach Alpha is that the reliability of the structure is counted with the correlation of its structure not an absolute form. Therefore in order to evaluate the reliability in PLS both these measures are taken in use. The CR of a structure is resulted from a ratio where the numerator is the variance between the steuctures and its measures plus its measurement error. If the CR for every structure reaches over 0.7 it shows the internal stability proper for measuring model and if it\&apos;s goes under 0.6 it shows the lack of reliability.

Table7: Composite Reliability

\begin{tabular}{cc} 
& Composite Reliability \\
\hline ISO9001 & 0.928631 \\
\hline Product innovation & 0.788612 \\
\hline Operation & 0.821166 \\
\hline Lack of peripheral confidence & 0.799841
\end{tabular}

\subsection{Convergent validity}

The convergent validity is the second measure used for the fitness of the measuring models in PLS. TheAVE shows the average variance shared between each structure with it\&apos;s measures.

AVE shows the correlation between structure and its measures and the more the correlation , the more the fitness. If the AVE is above 0.5 it shows an acceptable convergent validity [13]. For some 
researchers the least acceptable amount is 0.4. as can be seen in the following table the convergent validity of two variables ISO and operation is proper what the product innovation is a little bit far from the average.

Table8: Convergent validity

\begin{tabular}{cc} 
& AVE \\
\hline ISO9001 & 0.621489 \\
\hline Product innovation & 0.597313 \\
\hline Operation & 0.697087 \\
\hline Lack of peripheral confidence & 0.56435
\end{tabular}

\subsection{The fitness of the structural model}

Restaurant remodel shows how the hidden variables are in connection with each other and unlike measuring models have nothing to do with the questions. To review Fitness of structural model two measures are taken and used including 1. Significance coefficient Z (T-values) and 2. Squares R or R2

\subsection{Fitting the total model}

The GOF scale is connected with the models of structural equations through which the researcher can start to control the fitness of the whole part after fitting the structural part and the measurement part. To review the Fitness in whole model only the GOF is taken and use. Three numbers in $0.01,0.25$ and 0.36 are known as weak, average in a strong amount for GOF (Vetzels et al. 2009). It is calculated through the following equation: $G O F=\sqrt{\overline{\text { communalatles }} \times \overline{R^{2}}}$

\begin{tabular}{ccc}
\multicolumn{3}{c}{ Table9: GOF scale } \\
& Communality & R Square \\
\hline ISO9001 & 0.621489 & 1.00000 \\
\hline Innovation & 0.397313 & 0.626704 \\
\hline Operation & 0.697087 & 0.472486
\end{tabular}

Therefore $\overline{\text { communalitues }}_{\text {equals to }}$ /57. According to R2 mentioned in above table R2 equals 0.36. In this sense GOF is calculated as follows:

$G O F=\sqrt{0.57 \times 0.36}=0.45$

According to three amounts $0.01,0.25$ and 0.36 are set as weak, average and strong, Vote GOF, of the $45 / 0$ show the strong fit of the model.

\section{The results from statistical analysis}

Using the smart PLS the correlation of the variables has been tested. To review the causative relation between the dependent and independent variables in approving the whole model the root 
analysis has been taken in use. The root analysis has been performed by a smart PLS 8.5. The results from the PLS output show that the ratio of kai square to freedom is less than 3 and and other indexes of fitness confirm the model\&apos;s fitness. The following table shows the significance coefficient and the results of the indicated hypothesis in brief:

Table10: The results of the hypothesis

\begin{tabular}{cccc} 
Result & Significance & standard & Hypothesis \\
\hline Approved & 22.74 & 0.68 & $\begin{array}{c}\text { The quality management of ISO 9001 } \\
\text { Affects products innovation }\end{array}$ \\
\hline Approved & 7.13 & 0.34 & $\begin{array}{c}\text { The quality management of ISO 9001 } \\
\text { Affects financial turnover }\end{array}$ \\
\hline Approved & 11.58 & 0.51 & $\begin{array}{c}\text { The nnovation affects the financial } \\
\text { turnover }\end{array}$ \\
\hline Rejected & 0.58 & - & $\begin{array}{c}\text { Lack of peripheral confidence affects } \\
\text { the relation between ISO and } \\
\text { innovation }\end{array}$
\end{tabular}

1. in the first hypothesis of the research it has been implied that the quality management of ISO 9001 effects the innovation of the product and the analysis between these two shows that according to table 10 the significance number between two variables is 22.74 and since this amount is more than 1.96 this hypothesis is approved on the other hand since the significance number is positive it has a direct effect.

2. in the second hypothesis of the research it has been implied that the quality management of ISO 9001 effects the financial turnover and the analysis between these two shows that according to table 10 the significance number between two variables is 7.13 and since this amount is more than 1.96 this hypothesis is approved on the other hand since the significance number is positive it has a direct effect.

3. in the third hypothesis of the research it has been implied that the quality management of ISO 9001 effects the innovation of the product and the analysis between these two shows that according to table 10 the significance number between two variables is 11.58 and since this amount is more than 1.96 this hypothesis is approved on the other hand since the significance number is positive it has a direct effect.

4. in the main hypothesis number4 of the research it has been implied that the lack of peripheral confidence of ISO 9001 effects the innovation of the product and the analysis between these two shows that according to table 10 the significance number between two variables is 0.58 and since this amount is less than 1.96 this hypothesis is rejected.

\section{Conclusions}

The results from testing the hypothesis show that the bilateral relation between the variables have been approved f the quality management of ISO 9001 affects the Innovation and financial turnover and also the innovation itself influences the financial turnover. But the mediating role of lack of peripheral confidence is not approved yet. In other words the quality management of 
ISO 9001 on Innovation and financial turnover is not effective through mediating role of lack of peripheral confidence therefore dancer of the main portion of the research is no.

Since there\&apos; $\mathrm{s}$ never been research with the same composition of variables the total results of This research cannot be compared with other researches. But as mentioned in background of the most important research is done the following could be mentioned Tehrani preceding studies, Hashmy $\neg$ Nzhad and polishing (2011) [5] and Flynn (1995), Vayhan (2002) noted[14].

Considering the results achieved from this research it could be said that the economical situation of the world and international decisions about this along with globalization of the economy ( in other words considering the lack of peripheral confidence in global economy) it is necessary for our country to enter such markets so that the managers and the companies wish great knowledge and commitment and making pure ideas try to increase the benefits and Financial turnover of the company along with the innovation in products.

On the other hand using the basics of comprehensive quality management will cause $\mathrm{ft}$ to reach positive results such as innovation, creativity, organizational maturity, increase in productivity, and improving the financial turnover along with increasing the benefits of the company. According to the predictions from quality experts in the future there will be two kinds of companies only, the ones which have performed the comprehensive quality management and the ones which have been crossed out[15]. About the effects of quality management on the operation of the company and the innovation it can be said that according to Spencer\&apos;s analysis model (1994) it can be assumed that performing quality management reflects an organic model supporting innovation, while the actions accompanying mechanical model postpone the innovation. To perform the innovation a variety of actions if needed[16]. Considering low number of similar researches, researchers suggest the people interested to make more Applied researches.

\section{References}

[1] Pour Hamidian, Fakhreiya, Ahmadi, Elham and Ghorbani, Samira.(2014). Effect of omprehensive Quality Management on evaluating and improving the qualitative and innovative operation. The third annual, national seminar of modern management sciences.

[2] Iranzadeh, Soleiman and Malek, Ali (2009). The effect of quality management system (ISO 9001) on Gauges Sigma. Journal of Management preceding studies, Issue 80 Spring 2001.

[3] Alavi, Farshad (2001). "System Management" Athena Publishing, Printing, Page 53.

[4] Flynn, B.B., Sakakibara, S., Schroeder, R., (1995). Relationship between JIT and total quality management: practices and performance. Academy of Management Journal 38 (5) 1325-1360.

[5] Tehrani, Reza, Hashmy $\neg$ Nzhad, Seyed Mohammad and seighali, Mohsen (2012). Assessing the impact of quality management system on the financial performance of stock markets. Journal of Finance, First Year, Issue IV.

[6] Hosni Tavabe, Abdullah, Kazemi, Mostafa and Maharati, Yaghub (2013). The impact of lack of environmental confidence on organizational innovation: the role of the organizational structure as interfering variable. Enterprise Resource Planning preceding studies, Volume 3, Issue 4.

[7] Hejazi, Rezvan (2012). The impact of lack of environmental confidence to determine the effects on the relationship between management accounting and performance in Iranian firms. Journal of Accounting and Auditing Management, Issue VIII. 
[8] Purazbari, Mustafa Ibrahim, Akbari, rafiei Rasht Abadi (2015). The impact of environmental uncertainty on financial performance, the role of mediator production flexibility. Third International Conference on Applied Research in Management and Accounting.

[9] Fazeli, Hassan and Rahimian (2013), reviewing the literature of Comprehensive Quality Management and innovation and its relation with trainings. Studies of management on disciplinary training, volume 1, (continuous21), 6th year.

[10] Benner M.J, Tushman ML. (2003), "Exploration, Exploration, and process management: the productivity Dilemma Revisited". Academy of management Review, 28 (2). 238-56.

[11] Farsijani, Hassan; Neiestani Samii, A. (2009). The Role of integration between TQM and technology management in determining quality and innovation functions. Journal of Information Technology Management, 2 (4), pp. 117-136.

[12] Dinh Thai Hoang, Barbara Igel, Tritos Laosirihongthong, (2006) "The impact of total quality management on innovation: Findings from a developing country", International Journal of Quality \& Reliability Management, 23 (9), 1092 - 1117.

[13] Hung R.Y.Y,liens b.y.yang b.kuo y.(2011). impacted tam and organizational learning on innovation performance in the high teeth industry international business review 20,213-225.

[14] Wayahan V. B. et al., (2002), ISO 9000 Certification The financia: The financial Performance Implication Total Quality Management. 217-23.

[15] Dervisios,k.n.(2011), the challenge of adaptation through innovation based on the quality of the innovation process, total quality management and busing less excellence 212(5), 553-566.

[16] Prajogo, D. I., \& Sohal, A. S. (2003). "The relationship between TQM practices, quality performance, and innovation performance". The International Journal of Quality\& Reliability Management, 20(8), 901-918. 